\title{
Original articles
}

\section{Cardiac assessment of veteran endurance athletes: a 12 year follow up study}

\author{
Stuart Hood, Robin J Northcote
}

\begin{abstract}
Objectives-Sustained aerobic dynamic exercise is beneficial in preventing cardiovascular disease. The effect of lifelong endurance exercise on cardiac structure and function is less well documented, however. A 12 year follow up of 20 veteran athletes was performed, as longitudinal studies in such cohorts are rare.

Methods-Routine echocardiography was repeated as was resting, exercise, and 24 hour electrocardiography.

Results-Nineteen returned for screening. Mean (SD) age was 67 (6.2) years (range 56-83). Two individuals had had permanent pacemakers implanted (one for symptomatic atrial fibrillation with complete heart block, the other for asystole lasting up to 15 seconds). Only two athletes had asystolic pauses in excess of two seconds compared with seven athletes in 1985. Of these seven, five had no asystole on follow up. Two of these five had reduced their average running distance by about 15-20 miles a week. One athlete sustained an acute myocardial infarction during a competitive race in 1988 . Three athletes had undergone coronary arteriography during the 12 years of follow up but none had obstructive coronary artery disease. Ten of 19 (53\%) had echo evidence of left ventricular hypertrophy in 1997 but only two $(11 \%)$ had left ventricular dilatation. Ten athletes had ventricular couplets on follow up compared with only two in 1985 . Conclusions-Although the benefits of moderate regular exercise are undisputed, high intensity lifelong endurance exercise may be associated with altered cardiac structure and function. These adaptations to more extreme forms of exercise merit caution in the interpretation of standard cardiac investigations in the older athletic population. On rare occasions, these changes may be deleterious.

(Br F Sports Med 1999;33:239-243)
\end{abstract}

Keywords: athletes; heart; bradycardia; electrocardiography (ECG); pacemakers

A sedentary lifestyle is a recognised important risk factor for cardiovascular disease. Habitual sustained aerobic physical activity, however, has been shown to be beneficial in terms of primary and secondary prevention of cardiovascular disease.$^{1-6}$ Indeed, the American Heart Association have recently recommended that all individuals, regardless of age, should include physical exercise as part of an overall programme of health promotion and disease prevention. ${ }^{7}$ Although many now participate in lifelong endurance exercise, the long term effects on cardiac structure and function are poorly documented. ${ }^{8-11}$ It is important therefore to document the features of the heart in older athletes to prevent cardiac pathology being mistakenly diagnosed, particularly as two recent studies have identified a surprisingly high prevalence of silent ischaemia ${ }^{12}$ and arrhythmia. ${ }^{13}$

In 1985 , a cohort of 20 male veteran endurance runners (all of whom participated exclusively in running) were recruited from the Scottish Veteran Harriers Club (current membership over 800). This group contained several record holders and national champions in their age group. They underwent cardiac evaluation and were compared with a control group. ${ }^{14}{ }^{15}$ None of the participants at that time were smokers or had a history of cardiac disease but the athletes were found to have a higher prevalence of ST depression on exercise testing, left ventricular hypertrophy (LVH), and profound bradycardia $\left(<35 \mathrm{~min}^{-1}\right)$. This study describes findings 12 years after the original study.

\section{Patients and methods}

Nineteen of the original 20 athletes (one had died in the interim) were successfully contacted and agreed to return for repeat screening during 1997. After a detailed clinical history and examination, standard 12 lead electrocardiography (ECG) and Bruce protocol exercise tolerance test were performed. Echocardiography including $\mathrm{M}$ mode was performed according to the recommendations of the American Society of Echocardiography. In addition, 24 hour Holter monitoring was undertaken using a Medilog Excel MR45 recorder (Oxford Instruments, Oxford, UK) as previously described. ${ }^{14}$ During ambulatory 24 hour ECG monitoring, athletes were instructed not to run, but to restrict themselves
Accepted for publication 8 April 1999 
Table 1 Characteristics of the study group with resting and exercise ECG findings

\begin{tabular}{|c|c|c|c|c|c|c|c|c|c|c|c|c|c|}
\hline Subject & Age & $\begin{array}{l}\text { Running } \\
\text { experience } \\
\text { (years) }\end{array}$ & $\begin{array}{l}\text { Current } \\
\text { miles per } \\
\text { week }\end{array}$ & $\begin{array}{l}\text { Body } \\
\text { mass } \\
\text { index }\end{array}$ & $\begin{array}{l}\text { Blood } \\
\text { pressure }\end{array}$ & $\begin{array}{l}\text { Heart rate } \\
\text { (beats } / \mathrm{min} \text { ) }\end{array}$ & $\begin{array}{l}\text { PR interval } \\
(m s)\end{array}$ & $\begin{array}{l}\underset{\text { interval }}{\text { (ms) }} \\
\text { (ms }\end{array}$ & $\begin{array}{l}\text { QTTc } \\
\underset{\text { (ms) }}{(m s v a l}\end{array}$ & $\begin{array}{l}S V 1 / \\
R V 5 \\
(\mathrm{~mm})\end{array}$ & $\begin{array}{l}\text { ETT } \\
\text { time } \\
\text { (min) }\end{array}$ & $\begin{array}{l}\text { Max heart } \\
\text { rate } \\
\text { (beats/min) }\end{array}$ & $\begin{array}{l}\text { ETT/ ECG } \\
\text { abnormality }\end{array}$ \\
\hline 1 & 56 & 42 & 25 & 21.6 & $120 / 90$ & 46 & 212 & 88 & 486 & 44 & 21 & 163 & \\
\hline 2 & 66 & 44 & 50 & 21.5 & $144 / 86$ & 64 & 176 & 82 & 455 & 36 & 12 & 165 & $\begin{array}{l}3 \mathrm{~mm} \mathrm{ST} \\
\text { depression }\end{array}$ \\
\hline 3 & 65 & 47 & 25 & 18.6 & $142 / 78$ & 71 & 175 & 192 & 495 & & 11.2 & 142 & DDD paced \\
\hline 4 & 68 & 26 & 20 & 23.5 & $148 / 80$ & 49 & 198 & 94 & 400 & 23 & 12.16 & 161 & \\
\hline 5 & 75 & 54 & 9 & 21.7 & $110 / 68$ & 74 & 178 & 102 & 427 & 23 & 12.33 & 169 & \\
\hline 6 & 60 & 50 & 20 & 20.8 & $130 / 70$ & 42 & 208 & 82 & 415 & 25 & 15.67 & 145 & \\
\hline 7 & 64 & 48 & 50 & 20.7 & $140 / 88$ & 50 & 186 & 78 & 427 & 28 & 13.67 & 151 & $\begin{array}{l}3 \mathrm{~mm} \mathrm{ST} \\
\text { depression }\end{array}$ \\
\hline 8 & 72 & 45 & 0 & 23.5 & $120 / 75$ & 45 & 196 & 96 & 417 & 28 & 12 & 119 & \\
\hline 9 & 77 & 61 & 9 & 19.9 & $114 / 80$ & 86 & Paced & 158 & 444 & & 9.37 & 156 & Vent.paced \\
\hline 10 & 68 & 45 & 25 & 20.5 & $160 / 90$ & 43 & 204 & 92 & 411 & 41 & 12.53 & 161 & \\
\hline 11 & 69 & 50 & 55 & 17.8 & $165 / 70$ & 55 & 160 & 86 & 392 & 36 & 21 & 165 & \\
\hline 12 & 68 & 45 & 60 & 19.7 & $122 / 86$ & 54 & 206 & 82 & 424 & 47 & 17.56 & 175 & \\
\hline 13 & 66 & 44 & 70 & 20.2 & $112 / 70$ & 66 & 192 & 104 & 455 & 26 & 21 & 161 & \\
\hline 14 & 68 & 50 & 20 & 20.1 & $130 / 90$ & 42 & 228 & 82 & 461 & 21 & NO & ETT & \\
\hline 15 & 63 & 45 & 20 & 23.1 & $132 / 78$ & 58 & 154 & 98 & 459 & 13 & 12.45 & 144 & VEs \\
\hline 16 & 61 & 50 & 25 & 23.3 & $158 / 90$ & 55 & 238 & 90 & 394 & 21 & 13.16 & 165 & \\
\hline 17 & 64 & 46 & 50 & 20.7 & $150 / 70$ & 52 & 152 & 80 & 483 & 29 & 21 & 160 & Resting $\mathrm{T}$ inv \\
\hline 18 & 83 & 60 & 50 & 21.1 & $170 / 70$ & 70 & 136 & 104 & 444 & 20 & 11.18 & 156 & $\begin{array}{l}2 \mathrm{~mm} \text { ST } \\
\text { depression }\end{array}$ \\
\hline 19 & 66 & 45 & 70 & 20.4 & $118 / 86$ & 46 & 174 & 82 & 458 & 27 & 17 & 163 & Resting $\mathrm{T}$ inv \\
\hline
\end{tabular}

ETT, exercise tolerance test; DDD, dual chamber pacemaker; VE, ventricular ectopic; Vent, ventricular; inv, inversion.

to normal daily activities to allow comparison with the previous Holter monitor in 1985.

\section{Results}

Table 1 shows the characteristics of the participating athletes.

\section{RUNNING EXPERIENCE}

Mean (SD) miles run per week was 34 (21) compared with $43(26)$ in $1985(\mathrm{p}=0.08)$. One athlete (subject 8 ) had stopped running 4 years before follow up and two (subjects 5 and 9) were running only 9 miles each a week compared with 25 and 29 miles respectively in 1985. All other subjects continued to run at least 20 miles per week. Table 1 shows individual running experience.

\section{MORTALITY}

One athlete had died (aged 78) during the follow up period. His hospital case sheets confirmed that he had developed an organic brain syndrome with progressive deterioration in frontal and temporal lobe function in 1993. He died in 1994 from postoperative complications after repair of a strangulated femoral hernia. There was no suggestion that cardiac disease contributed to his demise.

\section{MORBIDITY}

Ischaemic heart disease

Subject 13 (aged 58 at the time) sustained an acute myocardial infarction 4 miles into a competitive race in 1988 . He was admitted to hospital where an acute infarct was confirmed by sequential ECG changes and a rise in cardiac enzymes. Subsequent coronary angiography was performed which disclosed minor irregularities in the left anterior descending artery including an atheromatous plaque in the proximal portion of the artery. This was thought to account for no more than a $20 \%$ reduction in luminal diameter. His cholesterol level was $6.6 \mathrm{mmol} / \mathrm{l}$, with a high density lipoprotein concentration of $0.95 \mathrm{mmol} / \mathrm{l}$. He was a lifelong non-smoker. He has returned to regular competitive endurance running without ill effect.

The follow up 12 lead ECG of subject 17 showed inferior and anterior $\mathrm{T}$ wave changes which had not been present on his 1985 ECG. This could have been consistent with athlete's heart but, as underlying coronary artery disease could not be excluded, he underwent an exercise myocardial perfusion scan which disclosed a fixed inferior perfusion defect. After further counselling he elected to undergo coronary angiography which showed normal coronary arteries.

\section{Exercise ECG (see table 1)}

Mean (SD) exercise time on the Bruce protocol was 14.8 (3.8) minutes. Only four athletes failed to reach their predicted maximum heart rate. Mean (SD) maximum heart rate on exercise was 158 (13) beats/min against a predicted maximum of 153 beats $/ \mathrm{min}$. Three subjects developed ST depression in excess of $2 \mathrm{~mm}$ on exercise without symptoms. Of these three, one had both echocardiographic and ECG evidence of LVH. The other two subjects had no evidence of LVH. One of these athletes (subject 18) had undergone coronary angiography in 1992 after the occurrence of chest pain while running. This had shown normal coronary arteries. Thallium perfusion scans were performed on all three individuals but no significant coronary perfusion abnormality was identified.

\section{Coronary angiography}

Two athletes underwent coronary angiography after the 1985 assessment, one because of ST segment depression on exercise (subject 3), the other on account of exercise induced ST depression and the concurrent finding of complete heart block and profound bradycardia (subject 9). Since 1985, three further athletes have had coronary angiography performed, one in 1988 because of myocardial infarction and intended continuing exercise (subject 13), another in 1992 because of the development of 
Table 2 Ambulatory ECG findings in the original study and at follow up

\begin{tabular}{|c|c|c|c|c|c|c|c|c|c|}
\hline \multicolumn{5}{|c|}{ Previous findings } & \multicolumn{5}{|l|}{ Present findings } \\
\hline Subject & $\begin{array}{l}\text { Minimum HR } \\
\text { (beats/min) }\end{array}$ & $\begin{array}{l}\text { Mean } H R \\
\text { (beats/min) }\end{array}$ & $\begin{array}{l}\text { Asystole (longest } \\
\text { pause) (s) }\end{array}$ & $\begin{array}{l}\text { Total No of } \\
\text { VEs }\end{array}$ & $\begin{array}{l}\text { Minimum } H R \\
\text { (beats } / \mathrm{min} \text { ) }\end{array}$ & $\begin{array}{l}\text { Mean } H R \\
\text { (beats/min) }\end{array}$ & $\begin{array}{l}\text { Asystole (longest } \\
\text { pause) (s) }\end{array}$ & $\begin{array}{l}\text { Total No of } \\
\text { VEs }\end{array}$ & $\begin{array}{l}\text { Heart } \\
\text { block }\end{array}$ \\
\hline 1 & 28 & 49 & 2.6 & 1 & 33 & 51 & & 17 & \\
\hline 2 & 41 & 64 & 2.5 & 10 & 36 & 55 & & 21 & \\
\hline 3 & 32 & 56 & & 18 & 65 & 72 & & 106 & Paced \\
\hline 4 & 46 & 68 & & 14 & 33 & 51 & 2.6 & 25 & $3^{\circ} \mathrm{HB}$ \\
\hline 5 & 50 & 76 & & 1652 & 50 & 74 & & 360 & \\
\hline 6 & 30 & 54 & 3.5 & 0 & 29 & 46 & 2.3 & 4026 & \\
\hline 7 & 32 & 52 & & 240 & 34 & 50 & & 0 & \\
\hline 8 & 32 & 49 & 2.4 & 0 & \multicolumn{4}{|c|}{ No Ambulatory ECG } & \\
\hline 9 & 17 & 49 & 15 & 7 & 86 & 92 & & 36 & Paced \\
\hline 10 & 29 & 48 & & 0 & 30 & 44 & & 165 & \\
\hline 11 & 43 & 61 & & 0 & 43 & 58 & & 1441 & \\
\hline 12 & 31 & 50 & 2.5 & 113 & 31 & 52 & & 13 & \\
\hline 13 & 39 & 53 & 2.8 & 12 & 38 & 62 & & 10931 & \\
\hline 14 & 46 & 63 & & 62 & 43 & 59 & & 703 & \\
\hline 15 & 42 & 64 & & 13 & 44 & 61 & & 121 & \\
\hline 16 & 40 & 68 & 2.5 & 12 & 37 & 60 & & 5 & $2^{\circ} \mathrm{HB}$ \\
\hline 17 & 37 & 64 & & 24 & 36 & 57 & & 5 & \\
\hline 18 & 42 & 60 & & 33 & 37 & 59 & & 808 & \\
\hline 19 & 38 & 56 & & 0 & 36 & 50 & & 35 & \\
\hline
\end{tabular}

$\mathrm{HR}$, heart rate; $3^{\circ} \mathrm{HB}$, third degree heart block; $2^{\circ} \mathrm{HB}$, second degree heart block; VE, ventricular ectopic.

chest pain and ST depression on his exercise ECG (subject 18), and a third in 1998 on account of resting ECG changes and an inferior perfusion defect on thallium scanning (subject 17). In four of these cases coronary angiography proved normal, the fifth disclosing minor disease in the left anterior descending artery only (subject 13).

Ambulatory ECG (see table 2)

Mean heart rate on 24 hour ambulatory ECG fell significantly $(\mathrm{p}=0.023)$ from 58 beats $/ \mathrm{min}$ in 1985 to 55 beats/min in 1997. In addition to the two with permanent pacemakers, a further six athletes had significant bradycardia (heart rate $<35 \mathrm{~min}^{-1}$ ). Of these, one (subject 4 ) had evidence of third degree atrioventricular block and seven asystolic pauses (longest $2.6 \mathrm{sec}$ onds), another (subject 6) had three asystolic pauses (longest 2.3 seconds), and a third (subject 16) had second degree heart block. All of these events occurred nocturnally. The two athletes with atrioventricular block had no heart block or pauses in 1985 and had not significantly altered their training regimens. Of seven athletes with asystolic pauses (longer than two seconds) in 1985, five had no asystole on follow up. Two of these five (subjects 1 and 16) had reduced their running mileage by an average of 15-20 miles per week. Eight subjects had $>50$ premature ventricular contractions per 24 hours compared with only four in 1985 . Ten athletes $(53 \%)$ had ventricular couplets on follow up compared with only two $(10 \%)$ in 1985. One athlete (subject 13) had 10931 premature ventricular contractions in 24 hours, having only had 12 in 24 hours in 1985. This presumably is a sequela of his myocardial infarction in 1988.

\section{Pacemaker insertion}

Two athletes had undergone pacemaker implantation in the follow up period. The first (subject 9) underwent pacemaker insertion at the age of 65 in 1985 after his initial assessment. ${ }^{14}$ Although asymptomatic at the time, his 24 hour ECG had shown 846 asystolic pauses ranging in length from 1.8 to 15 seconds. His resting nocturnal heart rate had been recorded as low as 17 beats/min and he also

Table 3 Echocardiographic findings in the original study and at follow up

\begin{tabular}{|c|c|c|c|c|c|c|c|c|c|}
\hline \multirow[b]{2}{*}{ Subject } & \multicolumn{4}{|c|}{ Previous findings } & \multicolumn{5}{|c|}{ Present findings } \\
\hline & IVS & LVIDd & LVIDs & $L V P W$ & IVS & LVIDd & LVIDs & $L V P W$ & Comments \\
\hline 1 & 1.12 & 4.76 & 3.3 & 1.28 & 1.3 & 4.24 & 2.66 & 1.36 & Trivial MR, LVH \\
\hline 2 & 1.46 & 4.49 & 3.02 & 1.31 & 1.34 & 5.02 & 2.69 & 1.41 & LVH \\
\hline 3 & 1.00 & 5.00 & 4.00 & 1.0 & 0.7 & 5.71 & 4.24 & 0.74 & Mild MR, E:A reversal \\
\hline 4 & 1.13 & 4.33 & 3.05 & 1.13 & 1.22 & 5.4 & 2.66 & 1.15 & LVH \\
\hline 5 & 1.15 & 4.97 & 3.45 & 1.33 & 1.47 & 4.3 & 3.22 & 1.13 & E:A reversal \\
\hline 6 & 1.06 & 3.84 & 2.93 & 1.06 & 1.20 & 4.52 & 2.09 & 1.02 & \\
\hline 7 & 1.21 & 4.97 & 3.58 & 1.09 & 1.7 & 3.56 & 1.24 & 1.53 & LVH \\
\hline 8 & 1.28 & 4.14 & 2.28 & 1.39 & 0.99 & 5.16 & 2.97 & 1.06 & Mild MR, AS $15 \mathrm{~mm} \mathrm{Hg}$ \\
\hline 9 & 1.15 & 5.94 & 4.36 & 1.21 & 1.27 & 5.33 & 4.31 & 0.92 & LVH \\
\hline 10 & 0.99 & 4.82 & 3.63 & 10.2 & 1.13 & 4.64 & 3.05 & 0.91 & \\
\hline 11 & 0.95 & 3.51 & 2.45 & 0.91 & 1.07 & 3.96 & 2.49 & 0.96 & \\
\hline 12 & 1.33 & 4.85 & 3.39 & 0.97 & 1.34 & 4.17 & 2.83 & 1.2 & Trivial MR \& AI, LVH \\
\hline 13 & 1.7 & 5.58 & 4.42 & 1.33 & 1.41 & 4.52 & 3.46 & 1.63 & LVH \\
\hline 14 & 1.4 & 3.9 & 2.94 & 1.25 & 1.1 & 4.9 & 3.6 & 1.1 & Mild MR \& AI. Dilated Aortic root $(4.6 \mathrm{~cm})$ \\
\hline 15 & 1.15 & 5.52 & 4.3 & 1.27 & 0.96 & 5.14 & 3.67 & 0.96 & \\
\hline 16 & 0.96 & 5.32 & 4.0 & 1.05 & 1.36 & 5.26 & 3.05 & 1.3 & LVH \\
\hline 17 & 1.01 & 4.41 & 2.89 & 1.1 & 1.07 & 4.86 & 2.77 & 0.9 & Mild MR \\
\hline 18 & & & & & 1.34 & 6.08 & 3.6 & 1.27 & Mild MR \& AI, LVH \\
\hline 19 & 1.33 & 4.79 & 3.39 & 1.45 & 1.2 & 4.45 & 2.4 & 1.27 & LVH \\
\hline
\end{tabular}

LVH, left ventricular hypertrophy; IVS, interventricular septum; LVIDd, left ventricular internal diameter in diastole; LVIDs, left ventricular internal diameter in systole; LVPW, left ventricular posterior wall; $\mathrm{MR}$, mitral regurgitation; $\mathrm{AS}$, aortic stenosis; $\mathrm{AI}$, aortic incompetence; $\mathrm{E}: \mathrm{A}$, mitral valve inflow, $\mathrm{E}$ and $\mathrm{A}$ waves. 
had evidence of first, second, and third degree atrioventricular block. After permanent pacemaker insertion, he reported increased energy and reduced times for a 10 mile run. The second (subject 3 ) had a pacemaker inserted at the age of 64 in July 1995. He had developed persistent atrial fibrillation with complete heart block and a resultant fall in exercise capacity. His 24 hour tape in 1985 had shown transient nocturnal heart block. After pacemaker insertion, he also anecdotally reported improved effort capacity and running times. Interestingly, both athletes had maximum heart rates of 139 and 141 on their Holter monitor in 1985 and so there was no evidence of chronotropic incompetence in either at that time.

\section{Lead ECG}

Two athletes with permanent pacemakers had uninterpretable ECGs. No significant interval change in mean PR, QRS, or QTc duration was observed. Of 17 athletes with interpretable ECGs, five (29\%) had Sokolow and Lyon criteria for LVH ( $\mathrm{s}$ in $\mathrm{V} 1$ plus $\mathrm{r}$ in $\mathrm{V} 5 / 6>35$ $\mathrm{mm}) \cdot{ }^{16}$ No change in mean sV1 plus $\mathrm{rV} 5 / 6$ was recorded on follow up.

Echocardiogram (see table 3)

Echocardiography identified 10 of 19 (53\%) with LVH (defined as interventricular septum and left ventricular wall thickness in excess of $12 \mathrm{~mm}$ ). Of those, nine had previous echo evidence of LVH in 1985. Two athletes with previously documented LVH had normal appearances on follow up, presumably as they had significantly reduced their training. Two athletes had dilated left ventricles $(>5.6 \mathrm{~cm}$ in diastole) compared with only one in 1985. Mild mitral incompetence was detected in eight $(42 \%)$ subjects, three of whom also had evidence of mild aortic incompetence. One subject (8) had minor calcific aortic stenosis (gradient $15 \mathrm{~mm} \mathrm{Hg}$ ).

\section{Discussion}

Regular physical exercise has undoubted health benefits, particularly on the cardiovascular system. Young athletic populations have been extensively studied and typical features of athlete's heart are well documented. ${ }^{17}$ Studies in older athletes with a long history of endurance training are rare. Indeed most studies of athletic populations are cross-sectional with few longitudinal reports in the literature..$^{8-11}$ The present 12 year follow up study therefore assessed a cohort of veteran male endurance runners who participate in exclusively dynamic exercise and who have had no exposure to occupational isometric exercise.

A control group might have been included in this study but a comparison between athlete and controls was made in the earlier papers. ${ }^{14} 15$ Ideally we would have wished to follow up the original control group from 1985 but this group of athletes had been lost to follow up. This being the case, the present study was designed to establish whether the abnormalities identified in the athletes in 1985 had advanced during the follow up period.
No significant changes were seen in either the incidence or severity of LVH during follow up. Dynamic exercise such as running is characteristically associated with the development of left ventricular dilatation and wall thickness enlargement. ${ }^{17}$ Our findings confirmed 1985 observations of a high incidence of LVH (53\%) but a much lower incidence of left ventricular enlargement $(11 \%)$ in this cohort. Older endurance athletes therefore appear to differ from their more youthful counterparts who participate in isotonic exercise and often display left ventricular dilatation. ${ }^{17}$ Consistent with previous observations was the regression of LVH in two athletes after detraining. ${ }^{10}{ }^{11} \mathrm{It}$ is unclear why few of our athletes have left ventricular dilatation. Most of them have maintained a similar intensity of training over four decades and it would be reasonable to assume that the effects of volume overload would be accumulative. Perhaps these athletes had dilated left ventricles in their youth but this has resolved as part of a physiological aging process.

Athlete's bradycardia is a well documented phenomenon which is generally considered benign. Asystolic pauses in excess of two seconds, which are predominantly nocturnal and require no intervention, are also not uncommon in athletic populations. ${ }^{12}{ }^{18-21}$ Cases of athletes requiring pacemaker insertion have been reported, however. ${ }^{12}{ }^{20}$ We have identified a further veteran athlete requiring pacemaker implantation who initially displayed transient nocturnal heart block, but ten years later subsequently developed persisting complete heart block with associated symptoms.

In 1985, seven of 20 athletes had asystolic pauses (longer than two seconds). Five of these had no asystole on follow up. Two of these five had reduced the intensity of their training regimen and this finding, consistent with a previous report by Ector et $a l^{20}$ is not unexpected. Although mean heart rate fell significantly, this was not of any clinical concern and we are reassured that there was no apparent progression of profound bradycardia or asystole. Our findings nonetheless suggest that clinically significant bradycardic problems are a real but rare potential complication of lifelong endurance exercise.

A higher prevalence of complex arrhythmias was evident on follow up compared with 1985. Jensen-Urstad et $a l^{13}$ have reported surprisingly high prevalences of arrhythmias in a similar population to ours. They noted complex ventricular arrhythmias in nine of 11 male veteran athletes compared with five of 12 controls. Interestingly, in 1985 no difference in the prevalence of ventricular arrhythmias between our athletes and controls was evident. This is consistent with the findings of Grimby and Saltin $^{22}$ who reported ventricular arrhythmias in only three of 33 middle aged athletes, suggesting that the prevalence of ventricular arrhythmias in athletic populations increases with aging.

This study also highlights the difficulty in interpreting the exercise ECG in athletic populations in an age group at greater risk of 
coronary artery disease. We identified three of 19 individuals who developed ST depression $>2 \mathrm{~mm}$ on exercise. Interestingly, in all cases, ECG changes resolved rapidly and were not associated with symptoms. To obtain further reassurance, however, and to prevent unnecessary prohibition of strenuous exercise, we performed myocardial perfusion scans to exclude occult coronary artery disease. All three had normal thallium scans and continue with their athletic activities. High incidences of perfusion defects have, however, recently been reported in young Swedish athletes with a low probability of coronary artery disease before the test. ${ }^{23}$ This raises concerns over the interpretation of myocardial perfusion scans in older athletes such as our group. Indeed Katzel et $a l^{12}$ recently found $16 \%$ of master athletes (mean age 63 ) to have silent myocardial ischaemia on exercise ECG and tomographic thallium scintigraphy.

In summary, we have identified that LVH persists in this group of veteran athletes and that it is not accompanied by the characteristic left ventricular dilatation seen in young endurance athletes. Bradycardic complications can occur in response to habitual lifelong endurance exercise but, with the exception of one subject who went on to develop complete atrioventricular block requiring pacemaker implantation, no clinically significant deterioration occurred. The difficulty in interpreting the ECG and exercise ECG in this cohort is evident, with three presumed false positive exercise tolerance tests. This highlights the need for knowledge of the features of athlete's heart in the elderly population to allow differentiation of pathology from normal variant.

To conclude, although athlete's bradycardia is generally a benign phenomenon, we have identified two lifelong runners who have required pacemaker implantation. During 12 years of follow up, however, none of the other athletes in our group developed clinically significant bradycardic problems. Longitudinal studies are required to establish whether lifelong strenuous exercise predisposes to bradycardic complications.

R J N performed the original studies in 1985 and devised the follow up study protocol. The echocardiograms, ETT, and 24 hour ambulatory ECGs were analysed by $\mathrm{S} \mathrm{H}$ who was blinded $\mathrm{N}$. Both authors will act as guarantors.
1 Morris CK, Froelicher VF. Cardiovascular benefits of physical activity. Herz 1991;16:222-36.

2 Chandrashekhar Y, Anand IS. Exercise as a coronary protective factor. Am Heart f 1991;122:1723-39.

3 Smith SC Jr, Blair SN, Criqui MH, et al. Preventing heart attack and death in patients with coronary artery disease. Circulation 1995;92:2-4.

4 Wenger NK, Froelicher ES, Smith LK, et al. Cardiac rehabilitation as secondary prevention. Clinical practice guideline no 17. Rockville, MD: US Department of Health and Human Services, Public Health Service, Agency for Health Care Policy and Research and the National Heart, Lung and Blood Institute, 1995:ACHCPR publication no 96-0672.

5 Pfaffenberger RS Jr, Hyde RT, Wing AL, et al. Physical activity, all cause mortality, and longevity of college alumni. N Engl F Med 1986;314:605-13.

6 Niebauer J, Hambrecht R, Velich T, et al. Attenuated progression of coronary artery disease after 6 years of multifactorial risk intervention: role of physical exercise. Circulation 1997;96:2534-41.

7 Fletcher GF, Balady G, Blair SN, et al. Statement on exercise: benefits and recommendations for physical activity programs for all Americans. Circulation 1996;94:85762 .

8 Nishimura T, Yamada Y, Kawai C. Echocardiographic evaluation of long-term effects of exercise on left ventricular hypertrophy and function in professional bicyclists. Circulation 1980;61:832-40.

9 Fagard R, Aubert A, Lysens R, et al. Non-invasive assessment of seasonal variations in cardiac structure and function in cyclists. Circulation 1983;67:896-901.

10 Murayama M, Kuroda Y. Cardiovascular future in athletes. In: Lubich T, Venerando A, ed. Sports cardiology. Bologna: Aulo Gaggi, 1980:401-13.

11 Dickhuth $\mathrm{HH}$, Horstmann T, Staiger J, et al. The long-term involution of physiological cardiomegaly and cardiac involution of physiological cardiomegaly and

12 Katzel LI, Fleg JL, Busby-Whitehead MJ, et al. Exerciseinduced silent myocardial ischaemia in master athletes. $\mathrm{Am}$ $\mathcal{f}$ Cardiol 1998;81:261-5.

13 Jensen-Urstad K, Bouvier F, Saltin B, et al. High prevalence of arrhythmias in elderly male athletes with a lifelong history of regular strenuous exercise. Heart 1998;79:161-4.

14 Northcote RJ, Canning GP, Ballantyne D. Electrocardiographic findings in male veteran endurance athletes. $\mathrm{Br}$ Heart f 1989;61:155-60.

15 Northcote RJ, McKillop G, Todd IC, et al. The effect of habitual sustained endurance exercise on cardiac structure and function. Eur Heart f 1990;11:17-22.

16 Sokolow M, Lyon TP. The ventricular complex in left ventricular hypertrophy as obtained by unipolar precordial and limb leads. Am Heart f 1949;37:161-86.

17 Oakley GDG. Sports cardiology. In: Julian DG, Camm AJ, Fox KM, et al, eds. Diseases of The heart. London: Saunders, 1996;1370-7.

18 Viitasalo MT, Kala R, Eisalo A. Ambulatory electrocardiographic recording in endurance athletes. Br Heart $\mathcal{f}$ 1982;47:213-20.

19 Viitasalo MT, Kala R, Eisalo A. Ambulatory electrocardiographic findings in young athletes between 14-16 years of age. Eur Heart $\mathcal{F}$ 1984;5:2-6.

20 Ector H, Verlinden M, Vanden Eynde E, et al. Bradycardia, ventricular pauses, syncope and sports. Lancet 1984;ii: 591-4.

21 Lown R, Wolf MA. Approaches to sudden death from coronary artery disease. Circulation 1971;44:130-42.

22 Grimby G, Saltin B. Physiological analysis of physically well-trained middle-aged and old athletes. Acta Med Scand 1996;179:513-26.

23 Bouvier F, Nejat M, Bergland B, et al. High incidence of scintigraphic myocardial uptake defects at rest and during exercise in male elite runners. Heart 1997;77:252-5.

\section{Take home message}

Although the benefits of moderate regular exercise are undisputed, high intensity lifelong endurance exercise may be associated with altered cardiac structure and function which on rare occasions may be deleterious. 